(2) Open Access Full Text Article

REVIEW

\title{
Erosive pustular dermatosis (chronic atrophic dermatosis of the scalp and extremities)
}

This article was published in the following Dove Press journal:

Clinical, Cosmetic and Investigational Dermatology

10 July 2013

Number of times this article has been viewed

\section{Kristina Semkova' \\ Georgi Tchernev² \\ Uwe Wollina ${ }^{3}$ \\ 'Department of Dermatology and Venereology, Sofia Medical University, \\ Sofia, Bulgaria; ${ }^{2}$ Policlinic for \\ Dermatology and Venereology, Saint \\ Kliment Ohridski University, Sofia, Bulgaria; ${ }^{3}$ Department of Dermatology and Allergology, Academic Teaching Hospital Dresden-Friedrichstadt, Dresden, Germany}

\begin{abstract}
Erosive pustular dermatosis is a rare noninfectious disease of the scalp or legs. Clinical findings are nonspecific, with crusts, atrophy, and pustules. A later complication of erosive pustular dermatosis is secondary cicatrical alopecia. The list of possible differential diagnoses is long, and includes infectious, inflammatory, and neoplastic dermatoses. Treatment is challenging. Topical drug therapy may improve the condition, but rarely results in a complete resolution. Surgery has been linked to exacerbation in some patients. In our hands, it achieved complete remission in male patients.
\end{abstract}

Keywords: erosive pustular dermatosis, scalp, cicatrical alopecia, leg, treatment

\section{Introduction}

Erosive pustular dermatosis (EPD) is a noninfectious inflammatory disorder that was described first in 1979 by Pye et al. ${ }^{1}$ The disorder occurs in two types: on the scalp and on the leg. We will review available data on the disease. Here, we present an update on this unusual dermatosis, with a special focus on treatment.

\section{Epidemiology}

EPD is a rarely reported entity, but the condition might be underrecognized, and its true frequency might be higher than previously thought. About 100 cases have been reported in the literature so far. ${ }^{2}$ Patton et al challenged the established concept of extreme rarity by finding eleven cases in a small region over a period of 3 years. They suggested that a focused search for the diagnosis and reconsideration of its main features, including the commonly seen lack of pustules, could lead to an increased rate of diagnosing EPD. ${ }^{3}$

EPD most commonly develops in the elderly. Rare cases of EPD in younger patients have also been reported. ${ }^{3}$ An infantile EPD in association with Klippel-Feil syndrome was observed in a 6-month old baby-girl. ${ }^{4}$ Although initially considered a female disease, EPD is encountered in both sexes, with a female predominance of approximately $2: 1$, $^{1,3}$ Specific geographical or racial distribution has not been demonstrated.

\section{Clinical presentation}

The typical clinical picture of EPD is a mixture of superficial erosions with crusts and pustules on atrophic skin (Figure $1 \mathrm{~A}$ and B). The number of pustules can vary remarkably, and sometimes they are absent. They often developed over several months or 



Figure I (A-C) Chronic eosinophilic dermatosis of the scalp in a 76 year-old male. (A) Overview. (B) Detail of crusted and erosive lesion with overgranulation. No signs of reepithelialization. (C) Excision and split-skin transplant. Ten days after transplantation, a stable transplant without recurrence is seen.

even years without improvement. Secondarily, cicatrical alopecia may develop. The lesions are not painful. Pruritus is uncommon. The course is progressive. No spontaneous remissions occur. ${ }^{1,3}$

On the leg, usually single lesions are found closely resembling chronic vegetating pyoderma. Scarring is a lesser problem than on the scalp. Edema and varicose veins are associated instead of skin atrophy.

\section{Histopathology}

Histopathology is uncharacteristic and not very helpful in confirming the diagnosis. However, a biopsy is important to exclude some of the differential diagnoses that may need different treatment or run another course. Histopathology shows subcorneal pustules, epidermal hypertrophy, or atrophy and erosions. The pustules, when present, are not of the follicular type, an important difference to bacterial folliculitis. These findings can be accompanied by a polymorphous dermal inflammatory infiltrate composed of neutrophil leukocytes, lymphocytes, and some plasma cells. In the neighborhood of erosions and ulcerations, a minimal leukocytoclastic vasculitis might be present. Microbial and mycological investigations remain negative. ${ }^{1}$

\section{Differential diagnosis (Table I)}

Tinea capitis or kerion celsi may resemble EPD, and mycological investigations are necessary in diagnostics. ${ }^{5}$ Other scalp disorders that need consideration include Gram-negative folliculitis, folliculitis decalvans, folliculitis et perifolliculitis abscedens et suffodiens, chronic vegetating pyoderma, superficial pyoderma gangrenosum, and others. ${ }^{6}$

A Tzanck smear test seems to be helpful in differential diagnoses to autoimmune vesiculobullous diseases like pemphigus. $^{7}$ Other types of cicatrical alopecia caused by lichen planopilaris or lupus erythematosus need to be differentiated. Histological examination is most helpful. ${ }^{3}$

In scalp EPD, field cancerization and squamous cell carcinoma are differential diagnoses (Figure 2). ${ }^{8}$ A number of elderly EPD patients had previously squamous cell carcinomas of the skin. ${ }^{9}$

Targeted therapies of cancer may induce EPD-like disease. Toda et al reported EPD-like lesions on the scalp during anti-epidermal growth-factor receptor gefitinib therapy. In their paper, a total of 11 cases were discussed. ${ }^{10}$

\section{Pathogenesis}

The etiology and exact pathogenesis of EPD remain unclear, which impedes proper categorization. Some authors consider EPD a disease in the spectrum of inflammatory dermatoses, whilst others claim immunological dysfunction as the main pathogenetic mechanism. Underlying factors include trauma and tissue damage, chronic inflammation, and neutrophilic dysfunction. ${ }^{3}$ 
Table I Differential diagnosis of erosive pustular dermatitis of the scalp (EPDS)

\begin{tabular}{|c|c|}
\hline Neonatal cephalic pustulosis & $\begin{array}{l}\text { Only in neonates, Malassezia furfur present, sebaceous gland hyperplasia, usually } \\
\text { neither crusts nor epidermal atrophy }\end{array}$ \\
\hline Kerion celsi & $\begin{array}{l}\text { Not much inflammation but severe destruction of hair follicles; pustules, oozing } \\
\text { lesions possible; potassium hydrochloride-stained scales or hairs for microscopy, } \\
\text { fungal culture }\end{array}$ \\
\hline Subcorneal pustular dermatosis & $\begin{array}{l}\text { Some authors suggest a closer relationship to EPDS, not restricted to the scalp, } \\
\text { blisters, hypopyon }\end{array}$ \\
\hline Autoimmune bullous diseases & $\begin{array}{l}\text { Direct immunofluorescence and autoantibody screening are helpful; histopathology } \\
\text { shows intra- or subepidermal blistering; among these disorders, pemphigus vegetans } \\
\text { comes closest clinically }\end{array}$ \\
\hline Lichen planus of the scalp & $\begin{array}{l}\text { Cicatrical alopecia with follicular papules, hyperkeratotic collars around the hair } \\
\text { shafts; histology shows lymphocytic infiltrates perifollicular and along the } \\
\text { dermoepidermal junction, hypergranulosis }\end{array}$ \\
\hline Chronic discoid lupus erythematosus & $\begin{array}{l}\text { Cicatrical alopecia; epidermal vacuolar basal cell degeneration and atrophy; dermal } \\
\text { mucin deposits; lymphocytic infiltrate, immunoglobulin } G \text { and } C 3 \text { deposits along the } \\
\text { dermoepidermal junction }\end{array}$ \\
\hline Folliculitis decalvans & $\begin{array}{l}\text { Follicular papules and pustules, Staphylococcus aureus present; paint brush sign of } \\
\text { bundles of residual hair, neutrophilic infiltrate }\end{array}$ \\
\hline Dissecting folliculitis & $\begin{array}{l}\text { Deep folliculitis with follicular destruction; subcutaneous liquefaction, oozing; later } \\
\text { keloid formation, can be associated with inverse acne (hidradenitis suppurativa) }\end{array}$ \\
\hline Chronic vegetating pyoderma & $\begin{array}{l}\text { Often in patients with impaired immune function; dermal abscesses due to } \\
\text { staphylococci and/or streptococci }\end{array}$ \\
\hline Superficial granulomatous pyoderma & $\begin{array}{l}\text { Slowly spreading superficial ulcerations, elevated enrolled border; histopathology } \\
\text { is uncharacteristic with neutrophils, vasculitis, vascular fibrin deposits, or thrombosis } \\
\text { of small vessels }\end{array}$ \\
\hline Field cancerization & $\begin{array}{l}\text { Epidermal atrophy, chronic sun damage; multiple actinic keratoses, and in advanced } \\
\text { cases squamous cell carcinoma are present; histopathology is most helpful }\end{array}$ \\
\hline
\end{tabular}

Leg lesions most commonly develop in patients with venous stasis and edematous skin changes. ${ }^{11} \mathrm{EPD}$ on the legs has also been reported in patients with paraplegia or quadriplegia. ${ }^{3,12}$

Trauma and tissue damage play a triggering role in EPD. ${ }^{13}$ Preceding herpes zoster, ${ }^{14}$ cochlear implant positioning, ${ }^{15}$ and iatrogenic injury caused by cryotherapy, topical chemotherapy, excisional surgery, imiquimod, ${ }^{16}$ grafting after surgery of nonmelanoma skin cancer ${ }^{17}$ topical methyl aminolevulinate

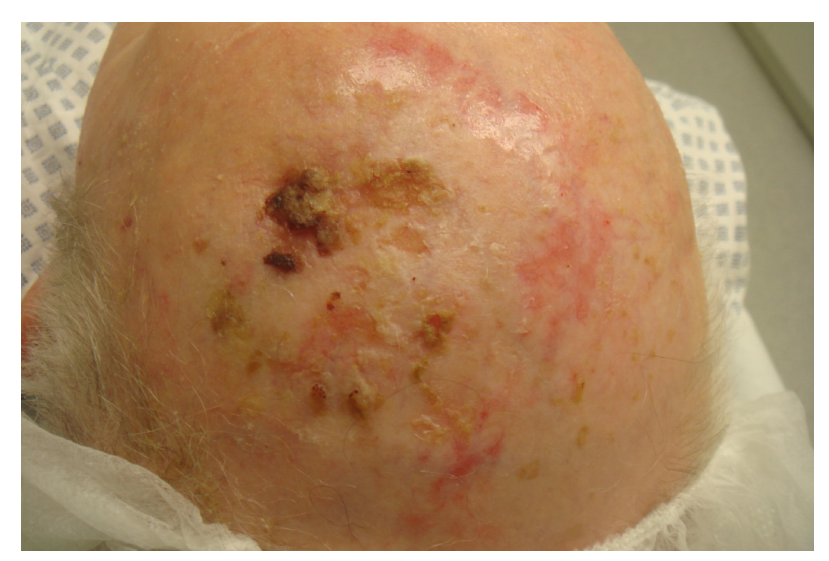

Figure 2 A 57-year-old patient with chronic actinic damage, multiple actinic keratoses and a T2 squamous cell carcinoma on the scalp. Field cancerization is an important differential diagnosis to erosive pustular dermatosis of the scalp. photodynamic therapy, ${ }^{18}$ and carbon dioxide laser therapy ${ }^{19}$ have all been reported in association with EPD.

Chronic ongoing inflammation is a feature of EPD. Neutrophils are commonly present, but do not predominate as in the specific neutrophilic dermatoses. ${ }^{3,20}$ Autoimmune diseases have been reported in association with EPD, although a direct pathogenetic link is difficult to establish., ${ }^{3,21,22}$ Positive antinuclear antibody testing was found in one study in four of eleven patients. ${ }^{3}$

Delayed wound healing is characteristic for EPD. The lack of hair bulge stem cells, estrogen deprivation, poor restorative capacity of aged keratinocytes, and chronic inflammation may be implicated in delayed healing., ${ }^{3,23}$

\section{Treatment (Table 2)}

EPD is a chronic condition that requires long-term management. Multiple therapeutic modalities have been tried, with high-potency topical corticosteroids being the mainstay of treatment. Topical and systemic antibiotics have been tried, with little or no response. ${ }^{1,18}$

The rarity of EPD and the scarce literature data impede the establishment of a treatment algorithm for the disease. Based on the available knowledge, it could currently be recommended that topical agents, corticosteroids, or tacrolimus 
Table 2 Therapeutic opportunities in erosive pustular dermatosis of scalp and leg

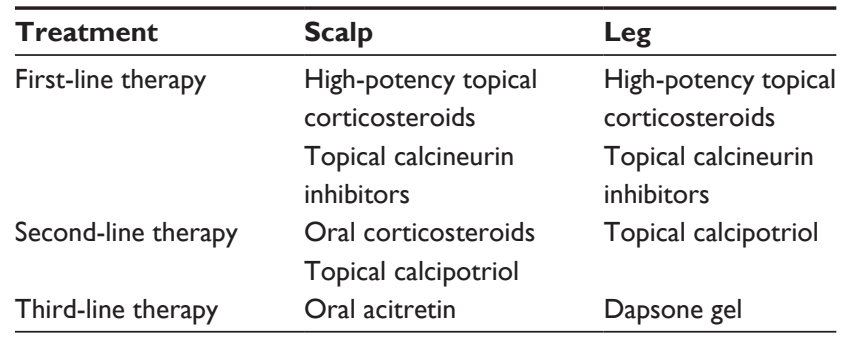

be tried first. All other reported modalities could be used as second-line treatments in recalcitrant cases.

\section{Medical drug therapy Corticosteroids}

High-potency topical corticosteroids have been used in most reported cases, with considerable efficacy and relative safety. ${ }^{1,22}$ The main disadvantage of this treatment is the possibility for skin atrophy, which should be considered in long-term application. Additionally, relapse after initial improvement has been reported after discontinuation of topical steroids. ${ }^{1}$

Guarneri and Vaccaro used oral steroids in tapering doses for 12 weeks to achieve complete resolution with residual scarring alopecia in a patient with photodynamic therapyinduced EPD. ${ }^{18}$ The side effects of systemic steroids and the available alternatives, however, do not justify this treatment approach.

\section{Topical tacrolimus}

Topical tacrolimus $0.1 \%$ ointment has emerged as an alternative to topical steroids with reported similar efficacy. ${ }^{14,15,24,25}$ Applied once or twice daily, it is effective not only for scalp but also for leg lesions. ${ }^{26}$ Improvement is seen after 1-2 weeks of treatment, but complete resolution may take up to 16 weeks, according to literature reports.

Topical tacrolimus could be used either as monotherapy, in combination with topical steroids, or as a follow-up treatment after an initial course of topical steroids. Long-term supportive treatment with tacrolimus twice weekly for 1 year prevented a relapse in a patient with EPD on the leg. ${ }^{26}$

Tacrolimus has an advantage over topical corticosteroids, since it does not cause skin atrophy. Furthermore, it has been reported to reverse EPD atrophy to a certain extent. ${ }^{24}$

\section{Dapsone}

Dapsone, an anti-inflammatory agent, has been tried in two patients, with disappointing results. ${ }^{1,2}$ Despite its antineutrophilic action, topical concentration after systemic administration might not reach therapeutic levels. ${ }^{2}$

Topical dapsone $5 \%$ gel, on the other hand, has been used in four patients, with total clearance of the lesions and a relatively long period without posttreatment recurrence. ${ }^{2}$ One patient was treatment-naive, but the other three failed to respond to previous treatment with corticosteroids, tacrolimus, antibiotics, ultraviolet therapy, and topical salicylic acid. Improvement was seen within 2 weeks to 2 months from therapy initiation, and complete resolution was observed for 1-4 months. No side effects were reported.

\section{Topical calcipotriol}

Boffa used calcipotriol cream $0.005 \%$ for a patient with scalp EPD with alopecia and resulted in a remarkable improvement after 8 weeks of treatment and partial hair regrowth after 12 weeks. ${ }^{27}$

\section{Acitretin}

Acitretin may be of some benefit in individual patients, but this drug needs regular laboratory monitoring. ${ }^{28}$ In conclusion, medical drug therapy for EPD shows a mixed response, with a need for long-term treatment - especially with topical drugs - and higher risk of relapses. Therefore, a maintenance treatment with topical calcineurin inhibitors has been recommended. ${ }^{29}$ On the other hand, stable complete resolutions have rarely been observed by conservative treatment.

\section{Photodynamic therapy}

Marked improvement was observed in a patient treated with photodynamic therapy, ${ }^{30}$ though there have been reports that it could itself trigger the development of EPD. ${ }^{18,31}$ Meyer et al used methyl 5 -amino levulinic acid cream with $630 \mathrm{~nm}$ irradiation for a total of two treatments, 1 week apart, leading to very good results at week $12 .{ }^{30}$ Although this might be considered as a third-line therapeutic option, photodynamic therapy should be used with caution in view of the conflicting reports.

\section{Surgery}

Since EPD of the scalp shows some mimicry of squamous cell carcinoma and field cancerization, surgery has been used occasionally. Deep excision and split-skin grafting leads to rapid healing. This should not be a first-line therapy of course. In cases of widespread and recalcitrant cases of bald elderly males, however, we observed complete remissions with an acceptable aesthetic outcome in three males aged 76-86 years. During follow-up of 12-36 months, no 
relapse occurred. Like in other chronic wounds, the removal of chronic granulation tissue and biofilm seems to be helpful in final wound closure. ${ }^{32}$

In contrast to our experience with scalp EPD, Eusen et al observed a recurrence of leg EPD after skin grafting. ${ }^{33}$ In their case, no complete excision of underlying skin had been performed. More data are needed to assess the possible role of surgery in EPD.

\section{Outlook}

A potential crucial step seems to interrupt the recruitment of neutrophils in the affected skin. Recently, new compounds have been identified that interact with neutrophil recruitment, like p38 mitogen-activated protein kinase inhibitor SB203580, ${ }^{34}$ Ac2-26 - an annexin A1/lipocortin 1 mimetic peptide ${ }^{35}$ - or antiadhesive proteins ${ }^{36}$ may expand current opportunities to control neutrophilic recruitment in EPD. However, a better understanding of the disease is desperately needed.

\section{Disclosure}

The authors report no conflicts of interest in this work.

\section{References}

1. Pye RJ, Peachey RD, Burton JL. Erosive pustular dermatosis of the scalp. Br J Dermatol. 1979;100(5):559-566.

2. Broussard KC, Berger TG, Rosenblum M, Murase JE. Erosive pustular dermatosis of the scalp: a review with a focus on dapsone therapy. $J \mathrm{Am}$ Acad Dermatol. 2012;66(4):680-686.

3. Patton D, Lynch PJ, Fung MA, Fazel N. Chronic atrophic erosive dermatosis of the scalp and extremities: a recharacterization of erosive pustular dermatosis. J Am Acad Dermatol. 2007;57(3):421-427.

4. Shimada R, Masu T, Hanamizu H, Aiba S, Okuyama R. Infantile erosive pustular dermatosis of the scalp associated with Klippel-Feil syndrome. Acta Derm Venereol. 2010;90(2):200-201.

5. Chia C, Dahl MV. Kerion mimicking erosive pustular dermatosis in elderly patients. Cutis. 2013;91(2):73-77.

6. Lugović-Mihić L, Barisić F, Bulat V, et al. Differential diagnosis of the scalp hair folliculitis. Acta Clin Croat. 2011;50(3):395-402.

7. Durdu M, Baba M, Seçkin D. The value of Tzanck smear test in diagnosis of erosive, vesicular, bullous, and pustular skin lesions. J Am Acad Dermatol. 2008;59(6):958-964.

8. Tsatsou F, Trakatelli M, Patsatsi A, Kalokasidis K, Sotiriadis D. Extrinsic aging: UV-mediated skin carcinogenesis. Dermatoendocrinol. 2012;4(3):285-297.

9. Wantz M, Perceau G, Goeldel AL, Grange F, Bernard P. Erosive pustular dermatosis of the legs: retrospective study of 16 cases. Ann Dermatol Venereol. 2011;138(2):93-99. French.

10. Toda N, Fujimoto N, Kato T, et al. Erosive pustular dermatosis of the scalp-like eruption due to gefitinib: case report and review of the literature of alopecia associated with EGFR inhibitors. Dermatology. 2012;225(1):18-21.

11. Cotterill JA, Lanigan SW. Erosive pustular dermatosis of the leg - a definition. Br J Dermatol. 1990;123(4):548.

12. Bull RH, Mortimer PS. Erosive pustular dermatosis of the leg. $\mathrm{Br} J$ Dermatol. 1995;132(2):279-282.

13. Grattan CE, Peachey RD, Boon A. Evidence for a role of local trauma in the pathogenesis of erosive pustular dermatosis of the scalp. Clin Exp Dermatol. 1988;13(1):7-10.
14. Kim KR, Lee JY, Kim MK, Yoon TY. Erosive pustular dermatosis of the scalp following herpes zoster: successful treatment with topical tacrolimus. Ann Dermatol. 2010;22(2):232-234.

15. Marzano AV, Ghislanzoni M, Zaghis A, Spinelli D, Crosti C. Localized erosive pustular dermatosis of the scalp at the site of a cochlear implant: successful treatment with topical tacrolimus. Clin Exp Dermatol. 2009;34(5):157-159.

16. Corradin MT, Forcione M, Giulioni E, Fiorentino R, Ferrazzi A, Alaibac M. Erosive pustular dermatosis of the scalp induced by imiquimod. Case Rep Dermatol Med. 2012;2012:828749.

17. Mehmi M, Abdullah A. Erosive pustular dermatosis of the scalp occurring after partial thickness skin graft for squamous cell carcinoma. $\mathrm{Br}$ J Plast Surg. 2004;57(8):806-807.

18. Guarneri C, Vaccaro M. Erosive pustular dermatosis of the scalp following topical methylaminolaevulinate photodynamic therapy. $J \mathrm{Am}$ Acad Dermatol. 2009;60(3):521-522.

19. Tavares-Bello R. Erosive pustular dermatosis of the scalp. A chronic recalcitrant dermatosis developed upon $\mathrm{CO}_{2}$ laser treatment. Dermatology. 2009;219(1):71-72.

20. Erdmann M, Kiesewetter F, Schuler G, Schultz E. Erosive pustular dermatosis of the leg in a patient with ankylosing spondylitis: neutrophilic dysfunction as a common etiological factor? Int J Dermatol. 2009;48(5):513-515.

21. Yamamoto T, Furuse Y. Erosive pustular dermatosis of the scalp in association with rheumatoid arthritis. Int J Dermatol. 1995;34(2):148.

22. Van Exel CE, English JC 3rd. Erosive pustular dermatosis of the scalp and nonscalp. J Am Acad Dermatol. 2007;57(2):11-14.

23. Archer DF. Postmenopausal skin and estrogen. Gynecol Endocrinol. 2012;28 Suppl 2:2-6.

24. Cenkowski MJ, Silver S. Topical tacrolimus in the treatment of erosive pustular dermatosis of the scalp. J Cutan Med Surg. 2007; 11(6):222-225.

25. Tardio NB, Daly TJ. Erosive pustular dermatosis and associated alopecia successfully treated with topical tacrolimus. J Am Acad Dermatol. 2011;65(3):93-94.

26. Dall'Olio E, Rosina P, Girolomoni G. Erosive pustular dermatosis of the leg: long-term control with topical tacrolimus. Australas J Dermatol. 2011;52(1):e15-e17.

27. Boffa MJ. Erosive pustular dermatosis of the scalp successfully treated with calcipotriol cream. Br J Dermatol. 2003;148(3):593-595.

28. Darwich E, Muñoz-Santos C, Mascaró JM Jr. Erosive pustular dermatosis of the scalp responding to acitretin. Arch Dermatol. 2011;147(2):252-253.

29. Vano-Galvan S, Antonio MC, Pedro J. Erosive pustular dermatosis of the scalp. J Pak Med Assoc. 2012;62(5):501-502.

30. Meyer T, Lopez-Navarro N, Herrera-Acosta E, Jose A, Herrera E. Erosive pustular dermatosis of the scalp: a successful treatment with photodynamic therapy. Photodermatol Photoimmunol Photomed. 2010;26(1):44-45.

31. López V, López I, Ramos V, Ricart JM. Erosive pustular dermatosis of the scalp after photodynamic therapy. Dermatol Online J. 2012;18(9):13.

32. Nusbaum AG, Gil J, Rippy MK, et al. Effective method to remove wound bacteria:comparison of various debridement modalities in an in vivo porcine model. $J$ Surg Res. 2012;176(2):701-707.

33. Eusen M, Fleuret C, Kupfer I, et al. Recurrence of pustular erosive dermatosis of the leg after a skin graft. Ann Dermatol Venereol. 2012;139(3):224-225. French.

34. Xu N, Hossain M, Liu L. Pharmacological inhibition of p38 mitogenactivated protein kinases affects $\mathrm{KC} / \mathrm{CXCL} 1$-induced intraluminal crawling, transendothelial migration, and chemotaxis of neutrophils in vivo. Mediators Inflamm. 2013;2013:290565.

35. Kamaly N, Fredman G, Subramanian M, et al. Development and in vivo efficacy of targeted polymeric inflammation-resolving nanoparticles. Proc Natl Acad Sci U S A. 2013;110(16):6506-6511.

36. Pliyev BK. Anti-adhesive proteins and resolution of neutrophil-mediated inflammation. Immunobiology. 2013;218(8):1085-1092. 


\section{Publish your work in this journal}

Clinical, Cosmetic and Investigational Dermatology is an interna- basic science researchers globally. This journal is indexed on CAS. tional, peer-reviewed, open access, online journal that focuses on the latest clinical and experimental research in all aspects of skin disease and cosmetic interventions. All areas of dermatology will be covered; contributions will be welcomed from all clinicians and

The manuscript management system is completely online and includes a very quick and fair peer-review system, which is all easy to use. Visit http://www.dovepress.com/testimonials.php to read real quotes from published authors.

Submit your manuscript here: http://www.dovepress.com/clinical-cosmetic-and-investigational-dermatology-journal 